\title{
Como cresce a Região Metropolitana do Rio de Janeiro? Uma comparação entre os Censos Demográficos de 2000 e 2010
}

\author{
Fernando Cardoso Cotelo ${ }^{1}$ \\ Juciano Martins Rodrigues ${ }^{2}$
}

\begin{abstract}
RESUMO
Este artigo discute o crescimento populacional recente e seus impactos na organização espacial de grandes cidades brasileiras, em particular da Região Metropolitana do Rio de Janeiro, considerando duas dicotomias presentes no discurso acadêmico em estudos urbanos no Brasil, as dicotomias "asfalto - favela" e "centro - periferia". Na literatura de antropologia urbana essas dicotomias fazem parte de estudos que utilizam a metáfora "cidade partida" como expediente interpretativo. Neste trabalho propomos uma metodologia que sistematiza a produção de alguns indicadores que lançam luz a certas regularidades observadas na escala da região metropolitana como um todo. A produção desse tipo de indicadores é uma forma de medir alterações registradas pelo Censo Demográfico do IBGE nos anos 2000 e 2010 na morfologia urbana de grandes cidades brasileiras. A metodologia utiliza conceitos bastante gerais e consagrados na teoria econômica aplicada a questões urbanas, a partir do modelo monocêntrico de localização residencial. Os resultados apontam para a expansão das metrópoles com acúmulo maior de população em áreas mais distantes de seus centros, ao mesmo tempo em que nota-se crescimento relativo da população em áreas de favelas mais próximas à região central.
\end{abstract}

Palavras-chave: configuração urbana; favela; periferia; crescimento urbano

\begin{abstract}
This paper discusses recent population growth and its impacts on the spatial organization of large Brazilian cities and more specifically of the Metropolitan Area of Rio de Janeiro while taking into consideration two dichotomies present in the Brazilian academic literature on urban studies: "asphalt - favela" and "centre - periphery". In the urban anthropology literature these dichotomies are part of studies that use the metaphor "divided city" as interpretive device. In this work we propose a methodology which frames the production of indicators that shed light on certain regularities observed at the scale of the Metropolitan Area. The production of this type of indicators is a way to measure changes registered by the Demographic Censuses of 2000 and 2010 on the urban morphology of large Brazilian cities. The methodology uses very general concepts consecrated in the urban economic literature stemming from the monocentric model of residential location.

\footnotetext{
${ }^{1}$ Doutor em Economia pela EESP-FGV. Pesquisa realizada no Observatório das Metrópoles - IPPUR UFRJ.

${ }^{2}$ Doutor em Planejamento Urbano pelo PROURB - UFRJ.
} 
The results point to the expansion of cities with larger accumulation of people in areas farther away from the centre and at the same time a relative growth of the population living in the favelas closer to the centre.

Keywords: urban configuration, favela, periphery, urban growth

\section{Introdução}

Transformações mais recentes na organização espacial das grandes cidades têm despertado cada vez mais a atenção de acadêmicos, policy makers e são objeto de investigação de urbanistas, economistas, geógrafos, demógrafos e planejadores urbanos.

Em uma série de estudos Alain Bertaud (Bertaud, 2001, Bertaud e Malpezzi, 2003 e Bertaud 2004) desenvolve argumentos que relacionam a estrutura e a organização espacial das cidades ao seu desempenho econômico e à possibilidade de seus planejadores implementarem políticas urbanas estratégicas no intuito de melhorar a qualidade ambiental, a infraestrutura urbana - notadamente a capacidade de transporte intraurbano -, promover a criação de empregos, habitação com padrões mínimos de qualidade e preços acessíveis ao mais pobres, entre outros objetivos.

Levando em consideração o fato de que a cidade é um objeto muito complexo e que esta complexidade advém de sua estrutura e forma em constante mutação, o autor sugere a adoção de modelos "simples o suficiente para que sejam facilmente compreendidos e precisos o suficiente para que sejam operacionalmente úteis" para representar sua organização espacial.

Devemos considerar, ao mesmo tempo, que compreender a organização espacial de grandes espaços urbanos torna-se também uma tarefa complexa. Desta maneira, mesmo que olhando apenas para uma das suas dimensões explicativas, neste caso a distribuição da população no território, é justificável e aceitável a utilização de olhares mais sintéticos, como o que pretendemos lançar aqui.

Para Bertaud (2001), o trabalho do planejador urbano seria identificar o tipo de organização espacial compatível com a estratégia municipal e as ferramentas regulatórias e investimentos em infraestrutura que permitiriam que a cidade evoluísse de sua organização espacial atual para outra implicada pela estratégia escolhida pelos planejadores urbanos. 
Parte-se do princípio de que as relações econômicas e sociais que deram origem ao surgimento das grandes cidades produziram no passado e permanentemente produzem o espaço construído. Esse espaço construído pode ser mapeado e medido.

Neste artigo, pretendemos olhar para a dinâmica interna do crescimento das cidades na última década considerando as duas dicotomias presentes no discurso acadêmico brasileiro em estudos urbanos. Lembramos que, na literatura de antropologia urbana, por exemplo, essas dicotomias fazem parte de estudos que utilizam a metáfora "cidade partida" como expediente interpretativo (Low, 1999). Asfalto é, na verdade, uma metonímia que se refere a territórios bem servidos de utilidades públicas, como ruas pavimentadas, iluminação pública, água e esgoto, escolas, postos de saúde e assim por diante, em oposição à favela, territórios onde reina a carência absoluta ou relativa desses mesmos serviços.

Centro e periferia têm seu significado literal: lugares centrais e lugares periféricos, geralmente se referindo à proximidade ou distância de um local onde predomina a oferta de emprego em uma área urbana, que pode ou não coincidir com seu centro geográfico.

No Brasil o termo periferia carrega um significado pejorativo, uma vez que representa um território de pobreza. Ao contrário dos Estados Unidos, as áreas periféricas das cidades brasileiras não são habitadas pela classe média afluente, mas predominantemente por pessoas pobres, uma vez que o padrão de distribuição espacial da população de diferentes grupos de renda no Brasil e na América Latina é invertido, com os grupos mais ricos ocupando o núcleo, sobretudo suas áreas centrais.

O trabalho recente de Nery et al. (2010) utiliza microdados do Censo Demográfico do IBGE para o ano 2000 e apresenta evidências de como a população nas favelas exibe renda mais baixa e piores indicadores de educação do que a parte "formal" do Município do Rio de Janeiro.

Preteceille e Valladares (2000), analisando dados do Censo Demográfico de 1991 e notando grande diversidade das favelas cariocas, fizeram as seguintes perguntas: "Será que as diferenças entre as favelas e os demais bairros pobres da cidade são suficientemente marcantes para que elas continuem a ser tratadas como conjuntos distintos?" e "Será que o grau de concentração da pobreza nas favelas justificaria a assimilação do grupo social ao tipo de espaço?". É bem possível que na maioria dos casos a ausência dos mesmos serviços públicos afeta favelas e periferias de forma semelhante, mas segundo esses autores há 
casos em que favelas apresentam melhores condições do que certos bairros pobres localizados na periferia.

Nesse sentido, o presente artigo procura uma forma de medir e representar o crescimento de metrópoles brasileiras baseado em dados dos Censos de 2000 e 2010. Queremos particularmente procurar responder se a cidade "cresce para o alto", mantendo altas densidades, ou se espalha, a partir de densidades menores. Ao mesmo tempo recortamos a análise separando os espaços considerados favelas (segundo a classificação do IBGE, que as considera "setores subnormais") dos espaços considerados como parte da "cidade formal". Assim, nos permitimos também perguntar qual cidade cresce, a formal ou a informal?

$\mathrm{O}$ artigo apresenta inicialmente uma série de indicadores básicos de população para os setores urbanos de 11 regiões metropolitanas brasileiras e a Região Integrada de Desenvolvimento de Brasília.

Esses indicadores procuram mostrar como variaram a população das regiões estudadas bem como sua composição segundo o critério de classificação de setores subnormais do IBGE, que são a variável mais próxima de que dispomos para indicar se o setor tem características de favela.

Propomos, desta maneira, uma metodologia que sistematiza a produção de alguns indicadores que lançam luz a certas regularidades observadas na escala da região metropolitana como um todo. A metodologia utiliza conceitos bastante gerais e consagrados na teoria econômica aplicada a questões urbanas, a partir do modelo monocêntrico de localização residencial originalmente desenvolvido por Von Thünen no final do século XIX em sua versão moderna consagrada a partir dos trabalhos de Alonso (1964), Muth (1969) e Mills (1967).

A vantagem da metodologia utilizada é que ela permite que dois aspectos cruciais relativos à configuração urbana sejam analisados simultaneamente para as favelas e para as periferias, permitindo comparações.

O Brasil, que ultrapassou a primeira década do século XXI com mais de 190 milhões de habitantes, vem se consolidando como um país metropolitano. Além disso, a concentração populacional permanece nas principais regiões metropolitanas. Em 1970, 15 principais regiões metropolitanas concentravam $27,2 \%$ da população brasileira, em 1980 esse percentual chegou a 31,7\%, passando a 34,9\% em 1991 e $36,1 \%$ em 2000 . O Censo 
2010 revelou que a população dessas 15 metrópoles continua respondendo por 36,3\% da população brasileira, portanto, não é correto afirmar que as metrópoles estariam passando por um processo de esvaziamento populacional. Pelo contrário, estes espaços tenderiam a manter sua força polarizadora, não apenas na dimensão demográfica, mas também econômica (Ribeiro, Silva e Rodrigues, 2011).

Ao mesmo tempo em que não seria correto considerar esse esvaziamento, é preciso dizer que há profundas alterações na distribuição populacional no interior de cada um desses espaços urbanos onde, embora não seja possível ainda afirmar um movimento de reversão da predominância dos núcleos, as periferias passam a crescer de maneira mais acelerada, com isso, toma maior relevância, nas análises sobre as transformações urbanas, as variáveis de distância e densidade.

\section{O uso da malha digital de setores censitários do IBGE para o cálculo dos indicadores}

A única base de dados disponível no Brasil que permite a construção de índices como os que apresentamos aqui, e que possui certo grau de comparabilidade entre as regiões metropolitanas estudadas, é a base de agregados de setores censitários do Censo Demográfico do IBGE conjugada com sua malha digital dividida por setores censitários.

A divisão dos setores censitários do IBGE consiste de uma malha de regiões onde se procuram extrair poucas informações sobre a maior parte (se possível a totalidade) dos domicílios e das pessoas residentes em cada um dos polígonos da malha para tornar possível o desenho da amostra de um questionário maior, no qual são recolhidas as informações que serão tratadas por técnicas de amostragem. Nosso interesse nessa base de dados está no fato de que ela se compõe das menores regiões em que é possível desagregar informações na dimensão geográfica.

Ocorre que o desenho da malha obedece a critérios que se relacionam com a conveniência da coleta de informações em termos de organização de equipes e logística do IBGE e não a critérios geográficos ou urbanísticos. Isto significa que não há uma regra rígida para a estipulação do tamanho de cada setor censitário. Existem setores da extensão de uma fração de quadra até vários quilômetros quadrados com densidades demográficas muito pequenas. Nestes casos, ainda que estejam classificados como urbanos, o território 
efetivamente construído costuma estar próximo a um dos vértices do setor. Há, por outro lado, diferenças entre as malhas censitárias utilizadas nos Censos de 2000 e de 2010.

Tomemos como exemplo a Região Metropolitana do Rio de Janeiro. Neste caso, o menor setor censitário em 2000 tem apenas $231 \mathrm{~m}^{2}$ e fica no centro de Niterói. O maior setor tem $128 \mathrm{~km}^{2}$ e está praticamente na zona rural abrangendo alguns subdistritos do município de Nova Iguaçu. Essa enorme diferença de escala introduz uma série de distorções nas medidas que compõem os índices que calculamos. Os setores pequenos aparecem nas áreas de maior densidade demográfica e os setores grandes aparecem nas partes mais periféricas e também, no caso dessa região topograficamente acidentada, nas partes altas dos morros e nas lagoas da cidade.

Ocorre que, para que seja viável a agregação dos valores de densidade populacional e distâncias que compõem os índices a serem estimados, é necessário fazer a hipótese de que toda a população se encontra no centro dos setores, o que obviamente não é verdade.

Uma fonte de erros de medida decorrentes da metodologia aqui utilizada é o fato de as distâncias serem calculadas a partir do centro geométrico e não do centro de massa do setor, uma vez que o IBGE trata os setores como se tivessem uma distribuição uniforme de habitantes. Como as periferias tendem a ser divididas em setores maiores, porém com densidades baixas, a agregação tenderá a fornecer uma distância média por habitante do setor ao CBD (Central Business District) ligeiramente maior do que a distância real.

\section{Indicadores básicos da distribuição da população no interior das regiões metropolitanas}

As Tabelas 1, 2 e 3 abaixo mostram, respectivamente, a composição da população nas regiões metropolitanas que habitavam os setores urbanos formais e favelas segundo o Censo de 2000, o Censo de 2010 e suas respectivas taxas de crescimento.

Como podemos observar na Tabela 1, há consideráveis diferenças entre a composição da população, levando em consideração a dicotomia não favela-favela, entre as regiões metropolitanas analisadas. Há lugares onde há uma maior presença da população em favela, como são os casos de Belém, Recife, Rio de Janeiro, Salvador, São Paulo e na Baixada Santista. Considerando a comparação entre as informações do Censo 2000 e do Censo 2010, percebemos que a população que habita favelas cresceu mais do que a 
população que habita as outras áreas da cidade em todas as RMs pesquisadas, com exceção de Curitiba e Goiânia.

Em Curitiba a população das favelas cresceu em ritmo menor do que a da chamada “cidade formal”. Em Goiânia, há que se destacar, houve uma diminuição significativa do número absoluto de moradores de favelas. Nesta região metropolitana, segundo os critérios do IBGE, não há população moradora em favelas em 2010.

Em algumas metrópoles há uma diminuição no número de habitantes nos setores não favela e um grande crescimento no número de habitantes dos setores favela. É notável o aumento na participação do número de pessoas que moram em favelas entre 2000 e 2010 em Recife e Salvador, onde o percentual passa, respectivamente, de $7 \%$ para $24 \%$ e de $9 \%$ para $27 \%$. Além de Belém, onde a população residente em favela passa de 33\%, em 2000, para 55\% em 2010. Isso aponta para uma possibilidade de reclassificação de setores realizada neste último Censo.

Tabela 1. População Urbana nas Regiões Metropolitanas em 2000

\begin{tabular}{|l|r|r|r|r|r|}
\hline \multirow{2}{*}{ RM ou RIDE } & \multicolumn{6}{|c|}{ população em 2000 } \\
\cline { 2 - 6 } & \multicolumn{1}{|c|}{ total } & não favela & \multicolumn{1}{c|}{ favela } & não favela & \multicolumn{1}{c|}{ favela } \\
\hline São Paulo & 16.976 .490 & 15.364 .620 & 1.611 .870 & $91 \%$ & $9 \%$ \\
\hline Rio de Janeiro & 10.581 .594 & 9.345 .798 & 1.235 .796 & $88 \%$ & $12 \%$ \\
\hline Belo Horizonte & 4.222 .745 & 3.795 .076 & 427.669 & $90 \%$ & $10 \%$ \\
\hline Porto Alegre & 3.526 .069 & 3.324 .512 & 201.557 & $94 \%$ & $6 \%$ \\
\hline Brasília & 2.706 .663 & 2.674 .645 & 32.018 & $99 \%$ & $1 \%$ \\
\hline Curitiba & 2.480 .357 & 2.316 .699 & 163.658 & $93 \%$ & $7 \%$ \\
\hline Salvador & 2.951 .814 & 2.696 .898 & 254.916 & $91 \%$ & $9 \%$ \\
\hline Recife & 3.214 .317 & 2.987 .877 & 226.440 & $93 \%$ & $7 \%$ \\
\hline Fortaleza & 2.867 .687 & 2.507 .330 & 360.357 & $87 \%$ & $13 \%$ \\
\hline Belém & 1.747 .863 & 1.167 .534 & 580.329 & $67 \%$ & $33 \%$ \\
\hline Goiânia & 1.614 .677 & 1.596 .671 & 18.006 & $99 \%$ & $1 \%$ \\
\hline Baixada Santista & 1.460 .505 & 1.271 .407 & 189.098 & $87 \%$ & $13 \%$ \\
\hline
\end{tabular}

Fonte: Elaboração dos autores com dados do Censo 2000. 
Tabela 2. População Urbana nas Regiões Metropolitanas em 2010

\begin{tabular}{|l|r|r|r|r|r|}
\hline \multirow{2}{*}{ RM ou RIDE } & \multicolumn{6}{|c|}{ população em 2010 } & \multicolumn{1}{c|}{ favela } \\
\cline { 2 - 5 } & \multicolumn{1}{|c|}{ total } & \multicolumn{1}{|c|}{ não favela } & \multicolumn{1}{c|}{ navela } & \multicolumn{1}{c|}{ navela } & $11 \%$ \\
\hline São Paulo & 19.583 .202 & 17.410 .754 & 2.172 .448 & $89 \%$ & $15 \%$ \\
\hline Rio de Janeiro & 11.739 .289 & 10.028 .117 & 1.711 .172 & $85 \%$ & $10 \%$ \\
\hline Belo Horizonte & 4.798 .866 & 4.308 .318 & 490.548 & $90 \%$ & $6 \%$ \\
\hline Porto Alegre & 3.841 .185 & 3.597 .869 & 243.316 & $94 \%$ & $4 \%$ \\
\hline Brasília & 3.512 .652 & 3.375 .527 & 137.125 & $96 \%$ & $6 \%$ \\
\hline Curitiba & 2.954 .511 & 2.772 .552 & 181.959 & $94 \%$ & $27 \%$ \\
\hline Salvador & 3.493 .694 & 2.562 .814 & 930.880 & $73 \%$ & $24 \%$ \\
\hline Recife & 3.590 .779 & 2.738 .776 & 852.003 & $76 \%$ & $12 \%$ \\
\hline Fortaleza & 3.469 .847 & 3.039 .684 & 430.163 & $88 \%$ & $55 \%$ \\
\hline Belém & 2.037 .376 & 906.784 & 1.130 .592 & $45 \%$ & $0 \%$ \\
\hline Goiânia & 2.124 .791 & 2.121 .296 & 3.495 & $100 \%$ & $18 \%$ \\
\hline Baixada Santista & 1.662 .299 & 1.360 .426 & 301.873 & $82 \%$ & \\
\hline
\end{tabular}

Fonte: Elaboração dos autores com dados do Censo 2010.

Tabela 3. Crescimento da população nas Regiões Metropolitanas de 2000 a 2010

\begin{tabular}{lrrr}
\hline \multicolumn{3}{c}{ RM ou RIDE } & \multicolumn{3}{c}{ crescimento em \% } \\
& total & não favela & favela \\
\hline São Paulo & $13 \%$ & $12 \%$ & $26 \%$ \\
Rio de Janeiro & $10 \%$ & $7 \%$ & $28 \%$ \\
Belo Horizonte & $12 \%$ & $12 \%$ & $13 \%$ \\
Porto Alegre & $8 \%$ & $8 \%$ & $17 \%$ \\
Brasília & $23 \%$ & $21 \%$ & $77 \%$ \\
Curitiba & $16 \%$ & $16 \%$ & $10 \%$ \\
Salvador & $16 \%$ & $-5 \%$ & $73 \%$ \\
Recife & $10 \%$ & $-9 \%$ & $73 \%$ \\
Fortaleza & $17 \%$ & $18 \%$ & $16 \%$ \\
Belém & $14 \%$ & $-29 \%$ & $49 \%$ \\
Goiânia & $24 \%$ & $25 \%$ & $-415 \%$ \\
Baixada Santista & $12 \%$ & $7 \%$ & $37 \%$ \\
\hline
\end{tabular}

Fonte: Elaboração dos autores com dados dos Censos 2000 e 2010.

A Tabela 4 apresenta as densidades médias calculadas para as regiões metropolitanas como um todo. Foram utilizados dois métodos de cálculo. Um, mais grosseiro, toma a população e divide pela soma das áreas dos setores censitários urbanos. 
O outro, mais preciso, divide a população dos setores urbanos por uma estimativa da área da mancha urbana obtida a partir da análise de fotos de satélite ${ }^{3}$.

3 Tais dados foram gerados a partir do projeto Sistema de Informação para Planejamento Territorial (SISPLAMTE-METRO), desenvolvido pela rede de pesquisa Observatório das Metrópoles. 
Tabela 4. Densidades médias estimadas para 12 regiões metropolitanas

\begin{tabular}{lrrrrr}
\hline RM ou RIDE & $\begin{array}{c}\text { Mancha } \\
\text { estimada (em } \\
\mathbf{k m}^{2} \text {, ano 2008) }\end{array}$ & $\begin{array}{c}\text { Áreas dos } \\
\text { setores } \\
\text { censitários } \\
\text { urbanos (em } \\
\mathbf{k m}^{2} \text {, ano 2010) }\end{array}$ & $\begin{array}{c}\text { População nos } \\
\text { setores urbanos } \\
\text { (Censo 2010) }\end{array}$ & $\begin{array}{c}\text { Densidade } \\
\text { média (pelo } \\
\text { sensoreamento } \\
\text { remoto) }\end{array}$ & $\begin{array}{c}\text { Densidade média } \\
\text { (pela malha digital } \\
\text { do IBGE) }\end{array}$ \\
\hline São Paulo & 1885 & 4882 & 19583202 & 104 & 40 \\
Rio de Janeiro & 1424 & 3035 & 11739289 & 82 & 39 \\
Belo Horizonte & 1040 & 2162 & 4798866 & 46 & 22 \\
Porto Alegre & 792 & 2289 & 3841185 & 49 & 17 \\
Brasília & 923 & 2087 & 3512652 & 38 & 17 \\
Curitiba & 654 & 1360 & 2954511 & 45 & 22 \\
Salvador & 479 & 1313 & 3493694 & 73 & 44 \\
Recife & 355 & 811 & 3590779 & 101 & 21 \\
Fortaleza & 579 & 1665 & 3469847 & 60 & 42 \\
Belém & 400 & 483 & 2037376 & 51 & 19 \\
Goiânia & 522 & 1118 & 2124791 & 41 & 17 \\
Baixada Santista & 299 & 967 & 1662299 & 56 & \\
\hline
\end{tabular}

Fonte: Elaboração dos autores com dados do Censo 2000. 
Como se pode notar, a densidade medida pelas imagens de satélite obtidas através de sensoriamento remoto produz estimativas consideravelmente maiores do que a densidade medida pelos setores censitários. O fato é que os setores considerados urbanos e de expansão urbana apresentam extensas áreas pouco povoadas. A medição feita a partir de fotos de satélite exclui áreas que os setores censitários não excluem.

\section{Distribuição espacial da população}

A Tabela 5 mostra a distância média do centro para cada cidade para todos os setores, para os setores não favela e para os setores favela. As colunas em porcentagem mostram a proporção do deslocamento das distâncias médias calculadas para o Censo de 2010 em relação àquelas calculadas para o Censo de 2000.

Tabela 5. Distância média ao CBD de 12 regiões metropolitanas brasileiras

\begin{tabular}{|c|c|c|c|c|c|c|}
\hline \multirow{3}{*}{$\begin{array}{l}\text { RM ou RIDE } \\
\text { São Paulo }\end{array}$} & \multicolumn{6}{|c|}{ distância média ao CBD } \\
\hline & \multicolumn{2}{|c|}{ todos } & \multicolumn{2}{|c|}{ não favela } & \multicolumn{2}{|c|}{ favela } \\
\hline & 18.5 & $3 \%$ & 18.5 & $3 \%$ & 18.4 & $3 \%$ \\
\hline Rio de Janeiro & 23.4 & $4 \%$ & 24.2 & $4 \%$ & 18.8 & $11 \%$ \\
\hline Belo Horizonte & 14.7 & $6 \%$ & 14.7 & $3 \%$ & 10.6 & $7 \%$ \\
\hline Porto Alegre & 20.8 & $3 \%$ & 21.4 & $4 \%$ & 12.8 & $-12 \%$ \\
\hline Brasília & 30.8 & $1 \%$ & 31.1 & $2 \%$ & 23.5 & $-1 \%$ \\
\hline Curitiba & 12.4 & $10 \%$ & 12.5 & $10 \%$ & 10.5 & $6 \%$ \\
\hline Salvador & 14.8 & $18 \%$ & 16.5 & $32 \%$ & 10.0 & $-17 \%$ \\
\hline Recife & 12.1 & $-2 \%$ & 12.1 & $-4 \%$ & 12.3 & $21 \%$ \\
\hline Fortaleza & 14.4 & $11 \%$ & 15.1 & $10 \%$ & 9.8 & $17 \%$ \\
\hline Belém & 11.6 & $18 \%$ & 12.6 & $24 \%$ & 10.8 & $18 \%$ \\
\hline Goiânia & 11.9 & $19 \%$ & 11.9 & $19 \%$ & 4.5 & $-25 \%$ \\
\hline Baixada Santista & 15.5 & $8 \%$ & 16.6 & $10 \%$ & 10.6 & $10 \%$ \\
\hline
\end{tabular}

Fonte: Elaboração dos autores com dados dos Censos 2000 e 2010.

Essa medida é calculada segundo a fórmula:

$$
\tilde{d}=\sum_{i=1}^{n} d_{i} w_{i}
$$

onde $d_{i}$ é a distância do centro do setor até o CBD e $w_{\tilde{i}}$ é a fração da população no setor. Calculamos três estimativas para cada uma das 12 regiões metropolitanas aqui 
consideradas, uma para a cidade como um todo, uma levando em consideração apenas os setores da cidade formal e outra apenas os setores favela.

A observação desses valores mostra como, sem exceções, a distância média para a cidade como um todo é sempre maior do que a distância média para os setores favela. Isso sugere a moradia na favela como uma possibilidade de morar mais próximo das áreas centrais concentradoras de emprego, aproveitando vantagens desta proximidade, entre elas a de poder economizar em gastos com transporte, ainda que para isso seus moradores tenham que estar submetidos a outras desvantagens, principalmente as relacionadas à infraestrutura urbana.

Em Porto Alegre, Brasília, Salvador e Goiânia a distância média ao centro para os moradores de favelas diminuiu em relação ao ano 2000, sendo que em Goiânia isso se dá pela praticamente não existência de setores favela.

Em Curitiba e Belém a distância cresceu menos que o crescimento da distância dos setores não favela. Em São Paulo e na Baixada Santista as distâncias cresceram no mesmo ritmo. No Rio de Janeiro, Belo Horizonte, Recife e Fortaleza as distâncias nos setores favela cresceram mais rápido do que nos setores não favela.

Isso aponta para condições específicas de cada região metropolitana que criam melhores ou piores condições para que favelas se instalem, seja na periferia seja no centro.

\section{O modelo monocêntrico de localização residencial e configuração urbana}

Não há espaço aqui para demonstrar formalmente o modelo de localização residencial desenvolvido por Alonso (1964), Mills (1967) e Muth (1969). A seguir apresentamos de uma forma intuitiva a lógica deste modelo monocêntrico de localização residencial.

Este modelo é o "cavalo de batalha" da economia urbana tradicional é já foi bastante estudado. Há muitas discussões formais acerca de suas propriedades e o leitor interessado deve consultar, por exemplo, as ótimas exposições de Fujita (1989), Brueckner (1987) ou Glaeser (2008). Aqui indicaremos apenas intuitivamente o mecanismo que faz com que as densidades estruturais na cidade descrevam uma trajetória descendente e côncava a partir do centro de emprego. 
Se o único atributo da terra fosse sua localização, todos os empregos de uma área urbana estivessem concentrados em uma pequena região (chamada na literatura de Central Business District, ou CBD) e o transporte de casa para o trabalho e do trabalho para casa tivesse um custo proporcional à distância do local onde se concentram os empregos, todos desejariam morar perto do centro para economizar em custos de transporte.

Em uma cidade onde existe um mercado imobiliário desenvolvido, padrões espaciais de densidade surgem em virtude do diferencial de preços da terra e da competição entre os habitantes por ofertas de renda aos proprietários.

Se for possível substituir capital por terra, os incorporadores (e indiretamente os consumidores) procurarão economizar no uso da terra mais cara. Como a terra mais cara é justamente a que se situa próxima ao centro de emprego, mais capital será adicionado a essa terra e os prédios aí serão mais altos.

Essa relação entre diferenciais de preços e custos de transporte é suficiente para gerar gradientes de densidade decrescentes a partir do local onde se encontram os empregos. Isto significa que a intensidade do uso da terra, segundo o modelo, deve diminuir à medida que se afasta do centro.

Assim o modelo é capaz de prever, entre outras coisas, que o aluguel pago por unidade de terra, a razão capital-terra, a densidade populacional e as alturas dos prédios, todos diminuem à medida que se afasta da região central onde estão concentrados os empregos, produzindo um gradiente de densidade negativamente inclinado e côncavo em relação à origem.

\section{O gradiente de densidade}

Estimar a densidade de uma área urbana não é trivial, pois as áreas urbanas têm muitos usos. Apesar da maior parte da área de uma cidade ser destinada à habitação, existem lotes destinados a usos comerciais e industriais, ruas e avenidas, parques, escolas etc.

A forma mais simples de medir a intensidade de uso do solo é simplesmente dividir a população do setor censitário pela área do setor. Além dos erros de medida mencionados na seção acima, deve-se notar que, ao utilizar toda a área do setor, estaremos medindo a intensidade incluindo todos os usos, sendo apenas uma aproximação. 
Para o cálculo dos gradientes das regiões metropolitanas aqui estudadas foram considerados os centros históricos das cidades como ponto central e calculadas as médias das densidades habitacionais para círculos concêntricos com incrementos de $1 \mathrm{~km}$ em seus raios, formando anéis concêntricos de $1 \mathrm{~km}$ de espessura cada.

Esse procedimento foi pela primeira vez utilizado por Colin Clark (1959) e é uma forma de representar o espaço bidimensional em uma dimensão, para que se possa evidenciar suas propriedades em relação a outras variáveis na forma de gráficos.

A equação a ser estimada é:

$$
d(r)=d_{0} e^{-\gamma r}
$$

onde $d(r)$ é a densidade de habitantes média dentro de cada anel em torno do CBD, que em nosso modelo é "explicada" por r $r$, a distância do centro de cada anel. O parâmetro $d_{0}$ é a densidade estimada no CBD e a função exponencial assume que essa densidade cai exponencialmente a partir do CBD segundo um gradiente dado por $\gamma$ e que não varia com a distância. O gradiente para cada região metropolitana estudada é o que queremos estimar através da forma estocástica e linearizada da equação acima:

$$
\ln d(r)=\ln d_{0}-\gamma r+\varepsilon
$$

onde $\ln d(r)$ é o logaritmo natural da densidade à distância $r$ do CBD e $\varepsilon$ é o erro do processo estocástico.

A função exponencial foi utilizada porque é a especificação mais simples que possui as propriedades requeridas para manter a consistência lógica do modelo.

Assim, passamos a analisar mais pormenorizadamente a Região Metropolitana do Rio de Janeiro. 


\section{A Região Metropolitana do Rio de Janeiro}

O mapa abaixo mostra a Região Metropolitana do Rio de Janeiro.

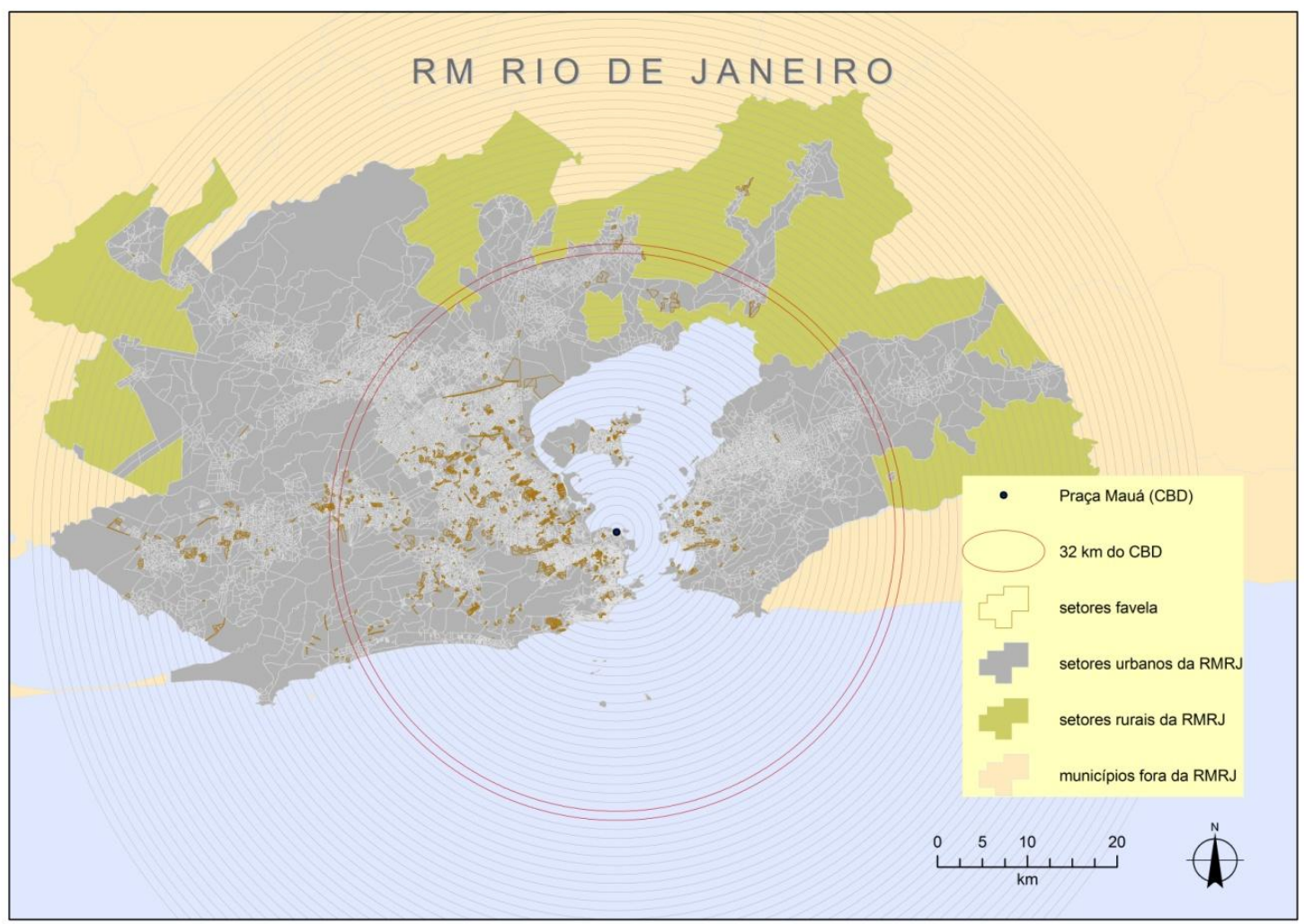

A área em cinza representa os setores urbanos e a área em verde os setores rurais. $\mathrm{O}$ ponto no centro do mapa em cor preta representa a localização da Praça Mauá. Para a elaboração dos gráficos a seguir foi utilizada a técnica de agregação por anéis concêntricos idealizada por Colin Clark (1959) para calcular os gradientes de densidade de cidades europeias no pós-guerra. Neste estudo estimamos o gradiente de densidade da Região Metropolitana do Rio de Janeiro.

Os anéis marcados no mapa têm 1 quilômetro de espessura. O primeiro anel, na verdade, é um círculo com um quilômetro de raio a partir do centro. O segundo anel começa a um quilômetro do centro e termina a dois quilômetros e assim por diante. $\mathrm{O}$ anel mais distante da Praça Mauá encontra-se a 72 quilômetros de distância.

Os setores subnormais do IBGE, que tomamos como proxies para as favelas, aparecem em coloração mais vibrante. O que se percebe é que a grande maioria dos setores está concentrada nas zonas norte, sul e centro do Rio de Janeiro e também na parte central 
de Niterói. A partir do anel a $32 \mathrm{~km}$ do centro estão as favelas da zona oeste do município do Rio de Janeiro, em geral próximas à Avenida Brasil. De fato, as favelas mais distantes do centro tendem a surgir próximas a vias de transporte, como a própria Avenida Brasil, a Via Dutra e as diversas linhas de trem. A marca de $32 \mathrm{~km}$ também corresponde aproximadamente ao ponto onde o gradiente de densidade cruza com a média da região metropolitana, exposta na Tabela 4, cujo valor é 82,5 habitantes por hectare como veremos no Gráfico 1 adiante.

Para a produção de uma análise mais apurada das mudanças na organização espacial da Região Metropolitana do Rio de Janeiro elaboramos três gráficos. O primeiro mostra o gradiente de densidade da região em 2010, o segundo relaciona a distância do centro à quantidade de pessoas que habitam o anel em 2010 e finalmente o terceiro apresenta a diferença da população em cada anel considerando os dados dos Censos de 2000 e 2010.

Tomando-se a soma dos habitantes de cada setor cujo centro está num anel, dividese pela soma das áreas dos setores e consegue-se uma estimativa da densidade em habitantes por hectare para cada anel a uma determinada distância do centro.

O Gráfico 1 representa a densidade média em habitantes por hectare no eixo vertical e a distância em $\mathrm{km}$ de cada anel; quando se considera a cidade como um todo, a densidade é representada pelos pontos em forma de círculo; quando se tomam apenas os setores correspondentes à cidade formal, é marcada com cruzes e, finalmente, quando se tomam apenas os setores considerados favelas, é assinalada por estrelas.

A primeira propriedade a se notar é que tanto a curva de gradiente de densidade para a cidade formal como para as favelas são negativamente inclinadas e aqui são aproximadas por curvas exponenciais.

Como se pode perceber, a densidade média dos setores favela é mais alta do que a dos setores formais na maior parte das medições e ao longo de todas as distâncias do centro.

Fazendo a correspondência com o Gráfico 2, que mostra a distribuição da população ao longo da distância marcada pelos anéis, podemos perceber a presença de dois picos, um por volta do $\mathrm{km} 8$ e outro por volta do $\mathrm{km} 20$. Se a densidade populacional fosse uniforme em toda a região metropolitana, descreveria um arco de parábola com seu ponto de mínimo no eixo vertical. Isso ocorre porque os anéis vão ficando cada vez maiores e, 
com uma densidade uniforme, sustentariam uma população que cresceria com o quadrado da distância ao centro. Mas, como vimos, a densidade é decrescente em relação à distância do centro, o que corresponde à distribuição que aumenta muito rapidamente nos primeiros anéis atingindo um ponto máximo local próximo ao $\mathrm{km} 10$. Em seguida a população decresce. Isso se deve à distribuição de espaços pouco povoados principalmente nas áreas de relevo acidentado e nas lagoas da cidade. O ponto máximo encontra-se próximo à distância de $20 \mathrm{~km}$ do centro. Isso significa que a maior população da cidade encontra-se a esta distância.

No Gráfico 2 a população habitante de favelas aparece representada pelas barras verticais na cor vermelha. A curva formada pelas barras vermelhas parece acompanhar aquela formada pelas barras azuis, que representam todos os setores da cidade, até próximo ao anel a $30 \mathrm{~km}$ de distância do centro. A partir daí a proporção de pessoas que moram em favelas diminui consideravelmente. Isto faz com que a distância média das favelas do centro seja menor do que a distância média dos setores da cidade formal. Vimos na Tabela 5 que a distância média ao centro para a RMRJ é de 23,4 km para a cidade como um todo, $24,2 \mathrm{~km}$ para os setores da cidade formal e $18,8 \mathrm{~km}$ para os setores favela.

Como vimos na Tabela 5, no Rio de Janeiro as distâncias nos setores favela cresceram mais rápido do que nos setores não favela, pela comparação entre 2010 e 2000 , enquanto os setores não favela aumentaram sua distância média.

O Gráfico 3 apresenta a diferença entre população de 2010 e de 2000 calculada pelo Censo. As barras azuis representam a totalidade da população para cada anel em 2010. As barras verdes representam a diferença entre a população de 2010 e 2000 nos setores não favela e as barras vermelhas representam essa diferença para os setores favela. Ele mostra que ao longo desses dez anos não houve grande acréscimo de população nos anéis mais próximos do centro exceto nos setores considerados favelas. De fato, até o anel a $15 \mathrm{~km}$ de distância do centro, a maior parte das barras verdes aponta para baixo, indicando perda de população. Em compensação, há barras vermelhas de magnitude semelhante apontadas para cima. Como se viu na Tabela 3, na RMRJ, enquanto a população da cidade formal cresceu apenas $7 \%$ nos últimos dez anos, a população favelada cresceu $28 \%$. A hipótese mais provável é que tenha havido reclassificação de setores nesses lugares mais próximos à região central. 
Por outro lado, a partir do anel a $15 \mathrm{~km}$, todas as barras verdes e vermelhas indicam valores positivos. Houve aumento de população tanto em setores da cidade formal como em setores favela a distâncias compatíveis com localizações nas partes mais distantes da zona norte, bem como a Baixada de Jacarepaguá e a Barra da Tijuca. Isso indica intensificação de uso nessas regiões tanto nos setores formais como favelas.

Entretanto, como a distância média nos setores favela cresceu mais do que nos setores da cidade formal, podemos dizer que houve criação proporcionalmente maior de domicílios distantes e em favelas, ainda que tenha havido reclassificação de setores próximos ao Centro.

A Região Metropolitana do Rio de Janeiro nos últimos dez anos aumentou em termos absolutos e relativos sua população favelada, intensificou o uso da terra em espaços periféricos e expandiu sua área urbana.

\section{Gráfico 1. Estimativas de densidade para a RMRJ}

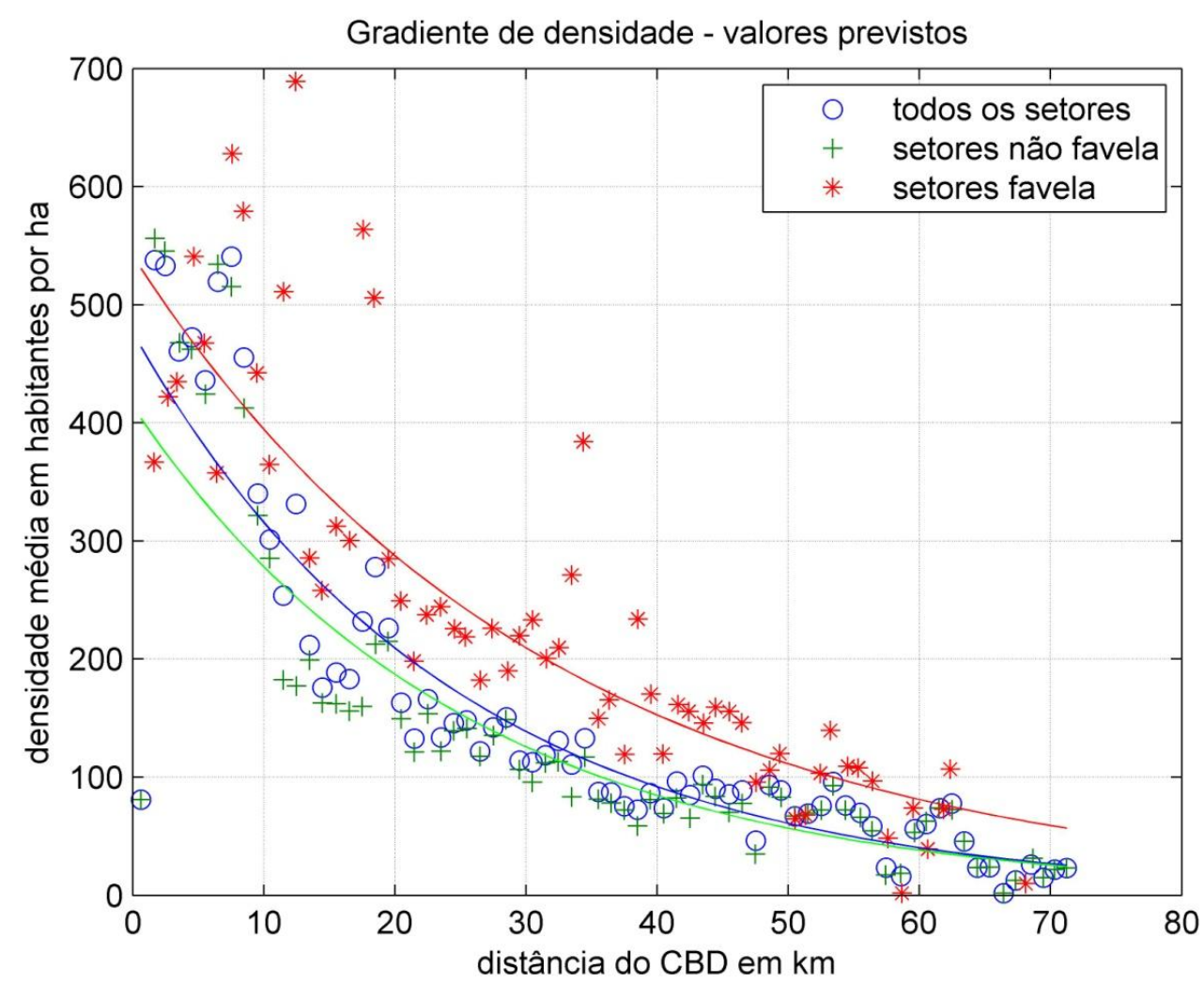




\section{Gráfico 2: Distribuição espacial da população na RMRJ}

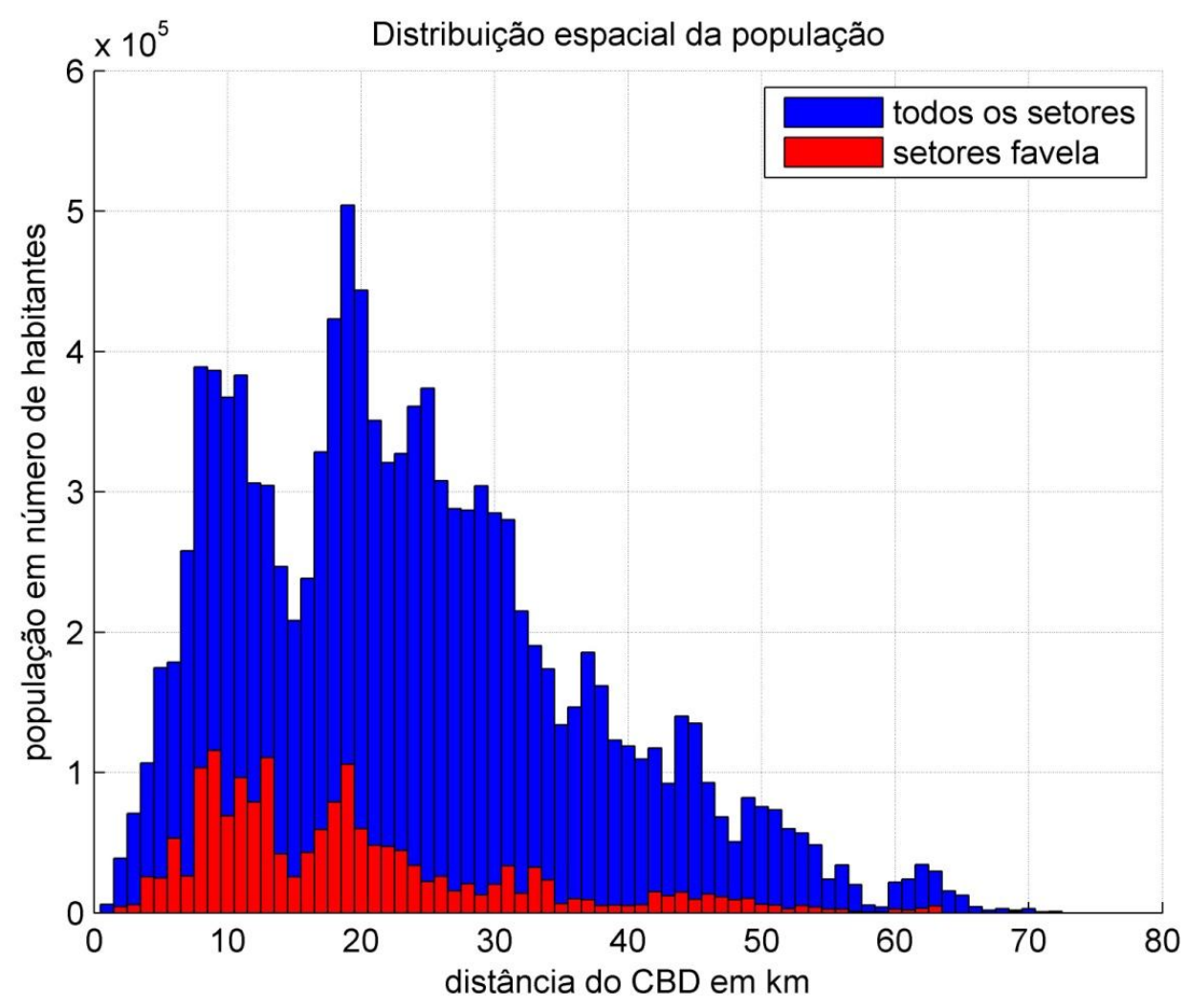


Gráfico 3. Distribuição da diferença de população do ano 2000 e do ano 2010 na RMRJ

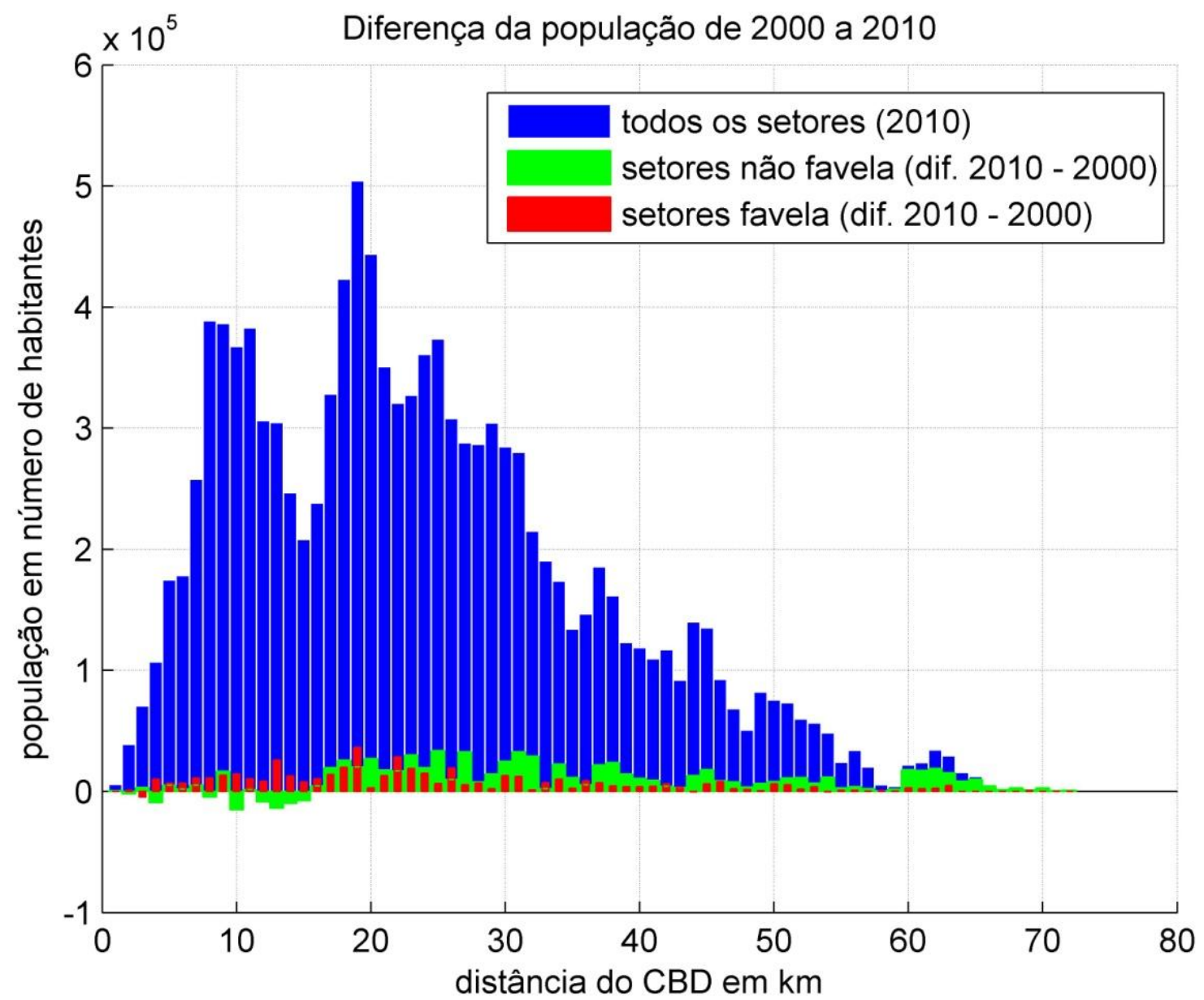

\section{Conclusão}

Ainda que o modelo monocêntrico seja bastante abstrato e pouco realista, ele é uma base teórica útil para a compreensão de certos fenômenos urbanos importantes. O principal deles é o fenômeno da queda de densidade com a distância do centro. Para a Região Metropolitana do Rio de Janeiro o fenômeno do gradiente de densidade decrescente é verificado a partir do Gráfico 1 apresentado anterioriormente.

Os indicadores e perfis calculados neste trabalho ajudam-nos a dar uma resposta preliminar à primeira pergunta. Nos casos que estudamos, os indicadores mostram uma tendência das cidades estudadas, sem exceção, a espalhar-se pela periferia, aumentando suas densidades em lugares mais afastados do centro. Em todas as regiões estudadas, com 
exceção de Recife, a distância média do centro para todos os setores aumentou de 2000 a 2010.

A razão para isto ter acontecido é o fato de que o acúmulo de população percebido ao longo dos últimos dez anos ter-se dado a distâncias maiores do que a média, indicando crescimento das cidades em áreas menos centrais. Isso confirma, como já dissemos acima, que o crescimento populacional se dá de forma mais acentuada na periferia das metrópoles e de forma menos acentuada, ainda que positiva, em seus núcleos.

Nosso estudo mostra que na Região Metropolitana do Rio de Janeiro a parte mais consolidada, a menos de $15 \mathrm{~km}$ da Praça Mauá, quase não sofreu nenhum adensamento. A partir daí, houve crescimento da população tanto na cidade formal como na favela. Em compensação nos municípios mais distantes grande parte da ocupação se deu nesses últimos dez anos. A presença de favelas ao longo da Avenida Brasil contribuiu para o aumento da extensão da área urbanizada na direção oeste. A RMRJ viu o crescimento de sua população favelada ser até quatro vezes maior do que o crescimento da população da cidade formal.

A causa pode ser em parte explicada pelo fato de que as favelas estão, na média, a mais do que $5 \mathrm{~km}$ mais próximas ao centro do que a cidade formal, a exemplo do que ocorre em outras metrópoles brasileiras.

\section{Referências biliográficas}

ALONSO, William. Location and Land Use. Cambridge, MA: Harvard University Press, 1964.

BERTAUD, Alain. Metropolis: A Measure of the Spatial Organization of 7 Large Cities. April, 2001. Disponível em:

http://alainbertaud.com/images/AB_Metropolis_Spatial_Organization.pdf (Acesso em 12/07/2012).

BERTAUD, Alain; MALPEZZI, Stephen. The Spatial Distribution of Population in 48 World Cities: Implications for Economies in Transition. 2003. Disponível em: http://alainbertaud.com/AB_Files/Spatia_\%20Distribution_of_Pop_\%2050_\%20Cities.pdf (Acesso em 11/07/2012). 
BERTAUD, Alain. The Spatial Organization of cities. 2004. Disponível em: http://alainbertaud.com/images/AB_The_spatial_organization_of_cities_Version_3.pdf (Acesso em 12/07/2012).

BRUECKNER, Jan. The Structure of Urban Equilibria: a unified treatment of the MuthMills model. In: MILLS, Edwin W. (ed.). Handbook of Regional and Urban Economics. Volume II. Amsterdam: Elsevier, 1987.

CARMONA, Marisa. The Regional dimension of the Compact City Debate: Latin America. In: JENKS, Mike; BURGESS, Rod (eds.). Compact Cities: sustainable urban forms for developing countries. New York: Routledge, 2008.

CLARK, Colin. Urban Population Densities. Journal of the Royal Statistical Society, 19, pp. $136-150,1959$.

DOWALL, David E., MONKKONEN, Paavo. Consequences of the Plano Piloto: The urban development and land markets of Brasília. Urban Studies, vol. 44, n. 10, pp. 1871-1887, 2007.

FUJITA, Masahisa. Urban Economic Theory: land use and city size. Cambridge, UK: Cambridge University Press, 1989.

GLAESER, Edward. Cities, Agglomeration and Spatial Equilibrium. New York: Oxford University Press, 2008.

LOW, Setha M. (ed.). Theorizing the City: The new urban anthropology reader. New Brunswick: Rutgers University Press, 1999.

MILLS, Edwin S. An Aggregative Model of Resource Allocation in a Metropolitan Area. American Economic Review 57(2), pp. 197-210, 1967.

MUTH, Richard. Cities and Housing. Chicago: Chicago University Press, 1969.

NERI, Marcelo (coord.). Desigualdade e favelas cariocas: a cidade partida está se integrando? Rio de Janeiro: FVG, CPS, 2010.

OJIMA, Ricardo et al. O estigma de morar longe da cidade: repensando o consenso sobre as "cidades-dormitório" no Brasil. Cadernos Metrópole, v. 13, n. 24, pp. 395-415, 2010 .

PRETECEILLE, Edmond; VALLADARES, Licia. Favela, favelas: unidade ou diversidade da favela carioca. In: RIBEIRO, Luiz Cesar de Queiroz. O futuro das metrópoles: desigualdades e governabilidade. Rio de Janeiro: Revan / FASE, 2000. 
RIBEIRO, Luiz Cesar de Queiroz; SILVA, Érica Tavares da Silva, RODRIGUES, Juciano Martins Rodrigues. Metrópoles Brasileiras: diversificação, concentração e dispersão. Revista Paranaense de Desenvolvimento. Curitiba: IPARDES, 2011. 